\title{
ACRF Instrumentation Status: New, Current, and Future
}

January 2007

James Liljegren

ACRF Instrument Team Coordinator

Work supported by the U.S. Department of Energy, Office of Science, Office of Biological and Environmental Research 


\section{Summary}

The purpose of this report is to provide a concise but comprehensive overview of Atmospheric Radiation Measurement Program Climate Research Facility instrumentation status. The report is divided into four sections: (1) new instrumentation in the process of being acquired and deployed, (2) existing instrumentation and progress on improvements or upgrades, (3) proposed future instrumentation, and (4) Small Business Innovation Research instrument development. New information is highlighted in blue text. 


\section{Contents}

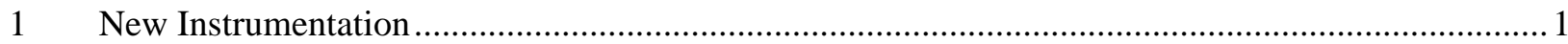

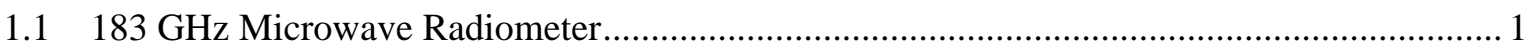

1.2 High-Frequency Microwave Radiometer ....................................................................... 1

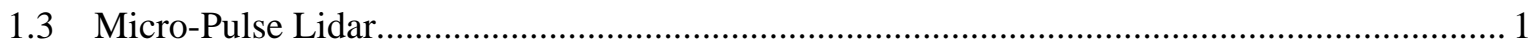

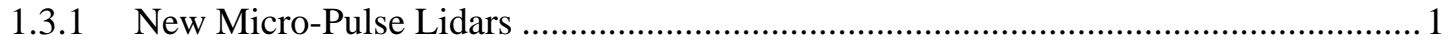

1.3.2 Upgrade Earlier Type-4 Micro-Pulse Lidars ....................................................... 1

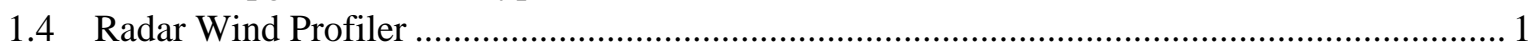

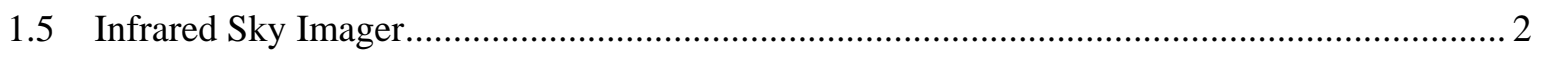

1.6 Add Multi-Filter Radiometers to Cessna 206.................................................................... 2

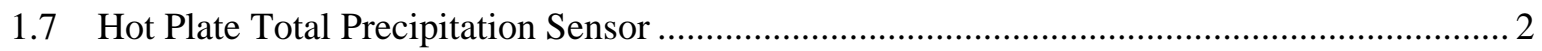

1.8 DigiCORA-III for Manus, Nauru ..................................................................................... 2

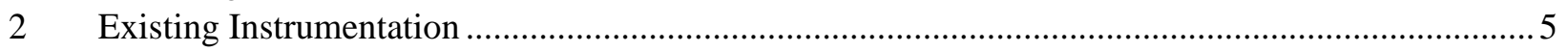

2.1 Atmospherically Emitted Radiance Interferometer .......................................................... 5

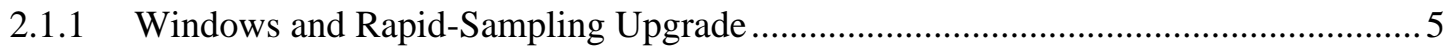

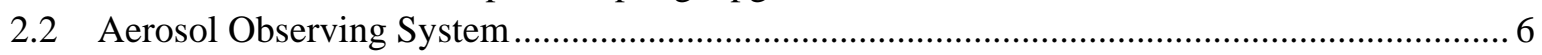

2.2.1 Reconfigure Southern Great Plains Aerosol Observing System ................................. 6

2.3 Balloon-Borne Sound System ......................................................................................... 6

2.3.1 Make Atmospheric Radiation Measurement Program-Barrow Soundings

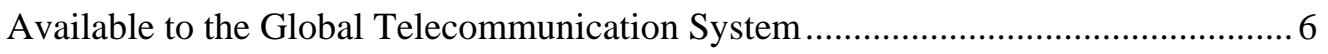

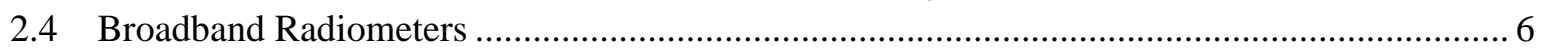

2.4.1 Pyrgeometer Calibration Improvements ............................................................. 7

2.4.2 Radiometer Calibration Facility Data Acquisition System Replacement .................... 7

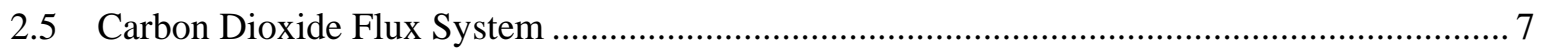

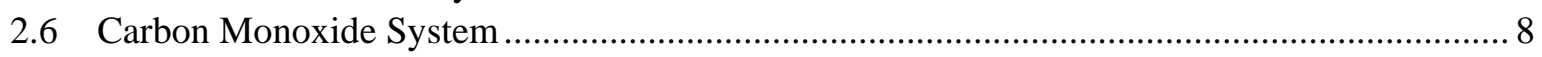

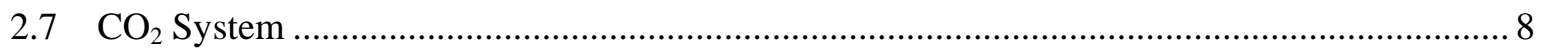

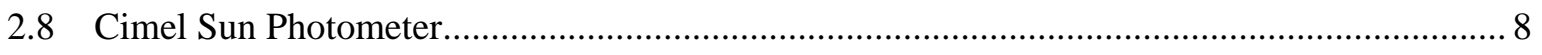

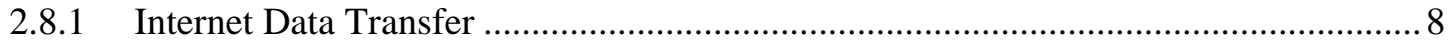

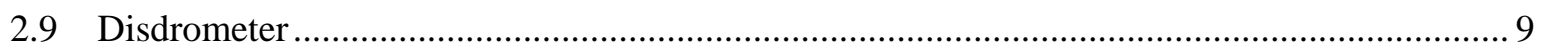

2.10 Energy Balance Bowen Ratio Station ........................................................................... 9

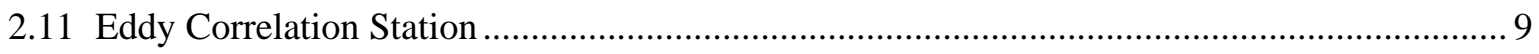

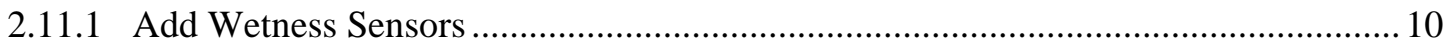

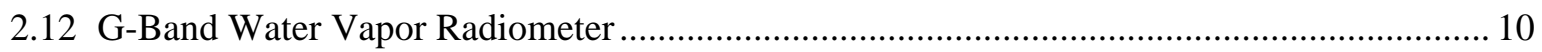

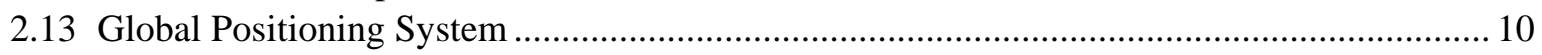

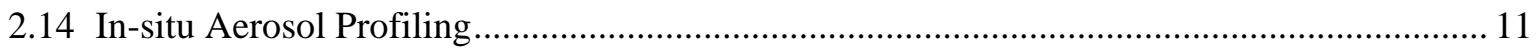

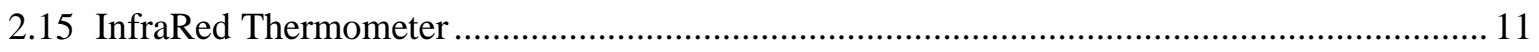

2.16 Multi-Filter Rotating Shadowband Radiometer and Related Systems ................................. 11

2.16.1 Filter-Detectors............................................................................................... 12

2.16.2 Multi-Filter Rotating Shadowband Radiometer Calibration and Data Processing

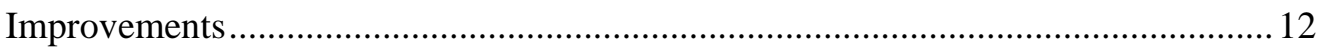

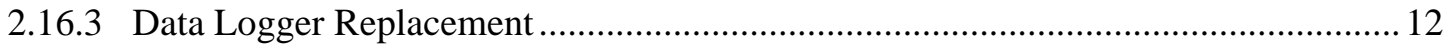

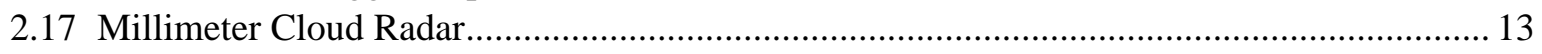

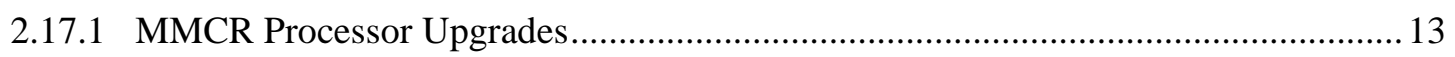

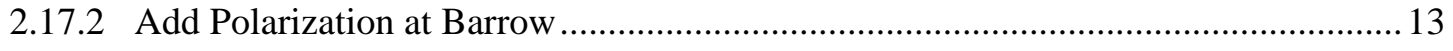

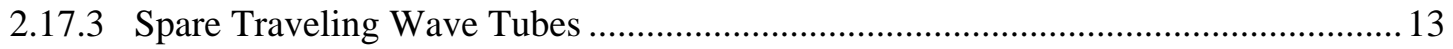


2.17.4 Millimeter Wave Cloud Radar Spectra Processing ................................................... 14

2.17.5 Refurbish Millimeter Wave Cloud Radar Antennas ................................................. 14

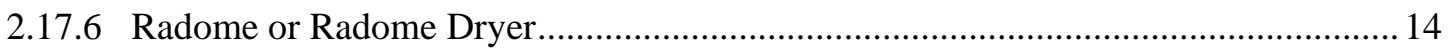

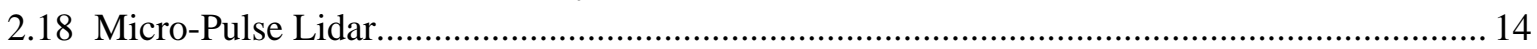

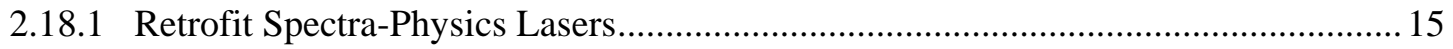

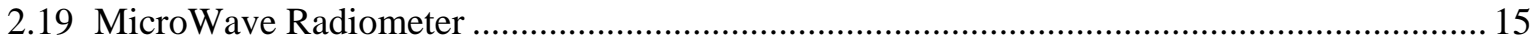

2.19.1 Unify MicroWave Radiometer Connectors............................................................ 16

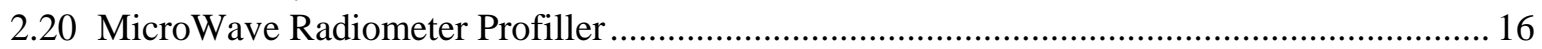

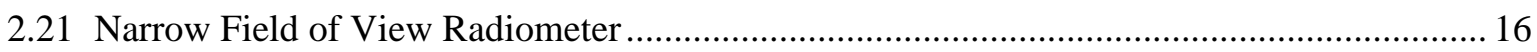

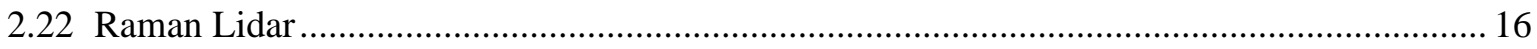

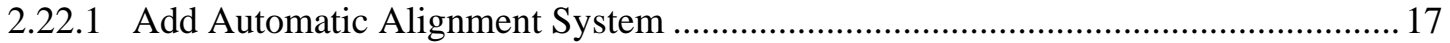

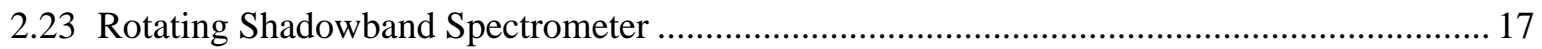

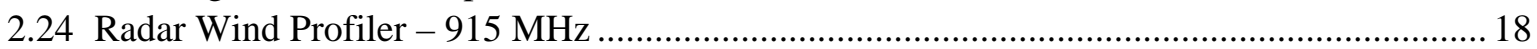

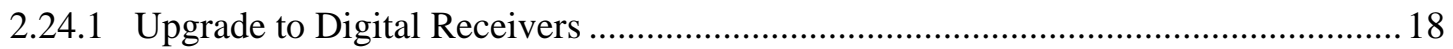

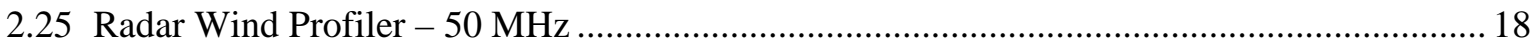

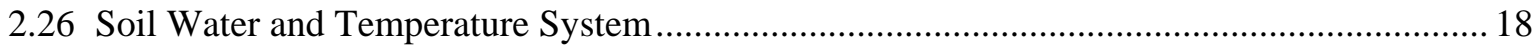

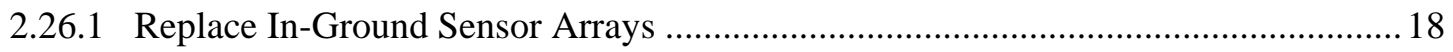

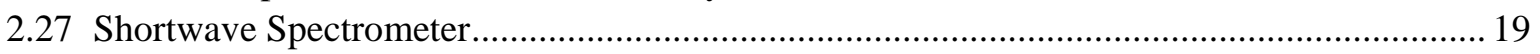

2.28 Surface Meteorological Instrumentation ........................................................................... 19

2.28.1 Develop Dynamic Rain Gauge Calibration Facility ................................................... 20

2.28.2 Create Atmospheric Radiation Measurement Program Climate Research Facility Wind Sensor Repair Facility ............................................................................ 20

2.28.3 Upgrade T/RH Probes and Wind Sensors for NSA Met Systems .............................. 20

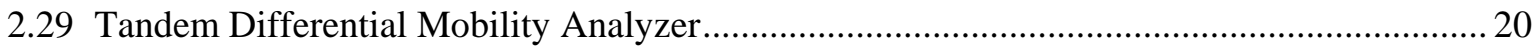

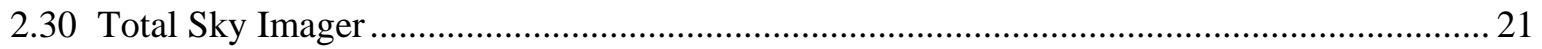

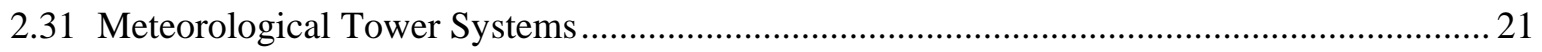

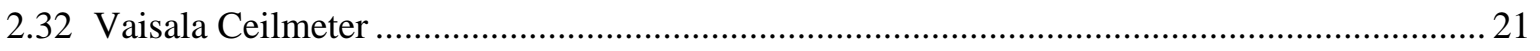

2.33 W-band Atmospheric Radiation Measurement Program Cloud Radar ................................. 22

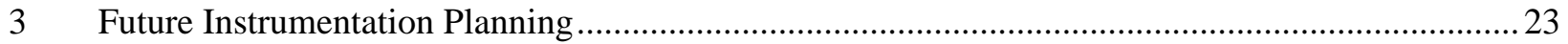

3.1 Atmospheric Radiation Measurement Program Volume-Imaging Array ............................... 23

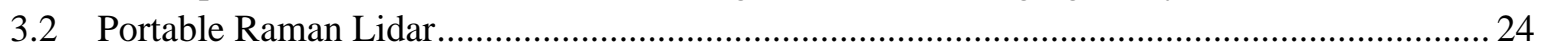

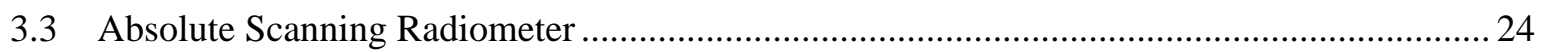

3.4 High-Resolution Oxygen A-Band and Water-Band Spectrometer....................................... 24

3.5 Rotating Shadowband Spectrometer Overhaul .................................................................. 24

3.6 Add 1.6 :m Channel to Multi-Filter Rotating Shadowband Radiometer and

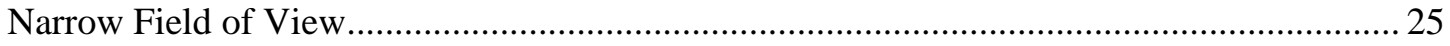

3.7 Aerosol Particle Sizing Spectrometer to Replace Optical Particle Counter at

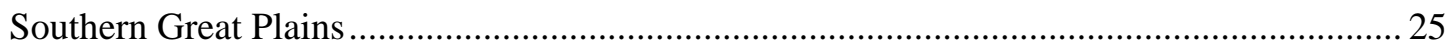

3.8 Future Microwave Radiometers .................................................................................. 25

3.9 Modified Muti-Filter Rotating Shadowband Radiometer for Liquid Water Path .................. 25

3.10 Infrared Thermometers for the Southern Great Plains Extended Facility Sites ..................... 26 
$4 \quad$ Small Business Innovation Research

4.1 Eye-Safe Ultraviolet Backscatter Lidar for Detection of Sub-visual Cirrus

4.2 Instrumentation for Remotely Sensing Aerosol Optical Properties -

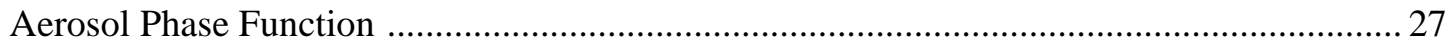

4.3 Unmanned Aerospace Vehicle-Suitable Cloud Radar......................................................... 27

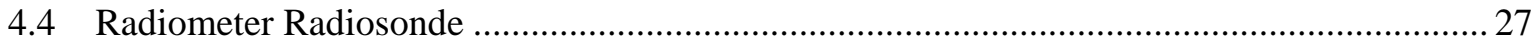

4.5 In-situ Measurement of Cloud Properties with Large Sample Volumes ................................ 28 


\section{New Instrumentation}

\section{1 $183 \mathrm{GHz}$ Microwave Radiometer}

Radiometrics Corporation has proposed to deploy at NSA-Barrow a new $183 \mathrm{GHz}$ microwave radiometer that they have developed under a DOE SBIR grant (ECO-00609).

STATUS - The radiometer will be deployed in late January or early February as part of the Radiative Heating in Under-explored Bands Campaign (RHUBC).

\subsection{High-Frequency $(90 / 150 \mathrm{GHz})$ Microwave Radiometer}

Mentor: Maria Cadeddu, Argonne National Laboratory

In response to the need for greater sensitivity (and therefore higher frequency) microwave channels to more accurately measure liquid water paths in thin clouds than the current 23.8/31.4 GHz instruments permit, a new High-Frequency Microwave Radiometer (MWRHF) has been acquired, and is currently deployed at SGP (ECO-00491).

STATUS - Deployment of the new MWRHF to the NSA-Barrow site has been delayed due to funding limitations associated with the Continuing Resolution. A second instrument, to be deployed with the ARM Mobile Facility in Germany, is currently on order.

\subsection{Micro-Pulse Lidar}

Mentor: Rich Coulter, Argonne National Laboratory

\subsubsection{New Micro-Pulse Lidars}

New MPLs are now operational at SGP, Barrow, Darwin, and Nauru (ECO-00577).

\subsubsection{Upgrade Earlier Type-4 Micro-Pulse Lidars}

STATUS - All three of the upgraded systems have successfully completed acceptance testing. One was installed on Manus Island in early December. One will be sent to Germany with the AMF. One will be a spare.

\subsection{Radar Wind Profiler}

Mentor: Rich Coulter, Argonne National Laboratory

A 4-panel $1290 \mathrm{MHz}$ RWP has been ordered from Vaisala for the 2007 AMF deployment in Germany. An operating frequency of $1290 \mathrm{MHz}$ was selected to match EU and other global frequency allocations for boundary layer radar profilers (ECO-00513). In July the FAA denied a request for a license to operate the new RWP at the SGP for testing prior to the AMF deployment to Germany in April 2007. The new RWP is in storage at SGP awaiting shipment to Germany. 


\subsection{Infrared Sky Imager}

Mentor: Vic Morris, Pacific Northwest National Laboratory

An IR sky imager from Blue Sky Imaging (http://www.aas.org/career/bluesky.html) was deployed at SGP in September 2005 to provide nighttime cloud cover measurements (ECO-00429). Problems with moisture infiltration of the imager necessitated its return to the manufacturer for repair/revision in October 2005. The unit was returned to SGP in late June and returned to service in August.

December 2006 - At the Cloud Properties Working Group meeting in Annapolis, Vic recounted the difficulties with the instrument and also in obtaining support from the instrument manufacturer. Vic is looking into other IR sky imaging systems that may be more satisfactory.

\subsection{Add Multi-Filter Radiometers to Cessna 206 (In-situ Aerosol Profiling aircraft)}

Currently, spectral albedo measurements are only possible at the SGP central facility using downward facing Multi-Filter Radiometers (MFR) on the 25-m level of the 60-m tower over a wheat field, and on a 10-m tower over the adjoining pasture. By adding a MFR to the Cessna 206 used for the In-situ Aerosol Profile (IAP), routine measurements of surface spectral albedo could be acquired over a broader area around the SGP central facility (ECO-00584).

STATUS - A statement of work has been developed to modify the aircraft to mount the MFR in the wing-tip extenders and incorporate it into the data acquisition system.

\subsection{Hot Plate Total Precipitation Sensor}

\section{Mentor: Mark Ivey, Sandia National Laboratory}

This is a new sensor developed by Roy Rasmussen at National Center for Atmospheric Research and commercialized by Yankee Environmental Systems. It offers the promise of handling under-catchment due to winds. The instrument has been installed in close proximity to a WMO-standard double fence inter-comparison reference (DFIR) shield and Geonor weighing precipitation gauge deployed by the NOAA Climate Reference Network (CRN). If the first sensor compares well with the CRN measurements, a second TPS could be acquired for mounting on the 40-m tower at Barrow to discriminate between blowing and falling snow. Acquisition of a TPS for Atqasuk may be desirable if the first unit proves successful at Barrow. (EWO-11696.)

STATUS - Data are available from the ARM Archive. The data files are named nsatpsC1.b1.

\subsection{DigiCORA-III for Manus, Nauru}

Mentor: Barry Lesht, Argonne National Laboratory

The digiCORA is the ground station for the Vaisala balloon borne sounding system. In FY 2003-2004 new digiCORA-III systems were acquired and deployed at SGP-CF, NSA-Barrow, and AMF as the 
primary ground station for those sites. For reliability and compatibility reasons it is necessary to replace the digiCORA-II systems at Manus and Nauru with the new digiCORA-III systems (ECO-00598).

STATUS - The new digiCORA-III units have been configured and shipped to the TWP for installation. 



\section{Existing Instrumentation}

This section describes the current status of the existing instrumentation, including any upgrades planned or in progress. The information is abstracted primarily from the Instrument Mentor Monthly Summary reports (available from the instrument web pages) and from ECO status updates.

\subsection{Atmospherically Emitted Radiance Interferometer}

Mentor: Dave Turner, Space Science and Engineering Center, University of Wisconsin

SGP - Both the OS/2-based AERI and the Windows XP-based AERI are operating nominally.

NSA - This Windows XP-based AERI is operating nominally. RFI continues to be a problem at this site. Efforts to try to reduce the RFI noise in the NSA-C1 data via post-processing of the raw data are on going.

TWP (Darwin) - This Windows XP-based AERI is out of service for repair, reintegration, realignment, and recalibration.

TWP (Nauru) - This Windows XP-based AERI is operating nominally.

AMF - This OS/2-based AERI is operating nominally.

Spare - The spare ER-AERI is being repaired and will be redeployed at Barrow in support of the Radiative Heating in Under-explored Bands Campaign (RHUBC). The OS/2-based spare AERI at SSEC would need to have the aging laser replaced in its interferometer before it could be sent to Darwin as a replacement.

\subsubsection{Windows and Rapid-Sampling Upgrade}

Migration of the AERI software from OS/2 Warp to Windows XP and related computer hardware modernization to enable rapid sampling of the IR spectrum at 10-s intervals was begun in FY 2004 (ECO00286). In FY 2005, 2 AERI systems were upgraded and installed at NSA-Barrow and SGP-CF. In 2006 the AERI systems at Darwin, Nauru, and the second system at Barrow were to be upgraded in the field. The laser in the second Barrow AERI failed while that system was being upgraded. The laser in the AERI at Darwin failed shortly after it was upgraded.

December 2006 - The TWP AERI system at Nauru has been upgraded (using the upgraded electronics rack recently transferred from Darwin) and appears to be operating properly. The recently replaced electronics rack at Nauru will be upgraded to serve as the electronics rack for the AMF AERI system. Work will begin to update that electronics rack as soon as it is received at UW-SSEC. 


\subsection{Aerosol Observing System}

Mentor: John Ogren and Anne Jefferson, National Oceanic and Atmospheric Administration/Earth System Research Laboratory/Global Monitoring Division

The CPC (Condensation Particle Counter) at SGP has been giving periodic error signals that indicate a problem with the instrument laser. All other instrument parameters are within acceptable range and the particle counts track well with the aerosol scattering values from the nephelometer. The CPC has been returned to the mentor for diagnosis and repair. The mentor has loaned a CPC (same model) to SGP until the AOS CPC is repaired.

\subsubsection{Reconfigure Southern Great Plains Aerosol Observing System}

The AOS at SGP will be reconfigured to have similar components and data acquisition system as the aerosol systems for AMF, NSA, and the IAP aircraft measurements over the SGP (ECO-00569). This work is scheduled for FY 2007.

\subsection{Balloon-Borne Sound System}

Mentor: Barry Lesht, Argonne National Laboratory

Overall radiosonde data recovery nominal was during the month, with NIM reporting 121 soundings of 124 scheduled (98\% recovery), NSA 46/60 (77\%), SGP 117/124 (94\%), TWP/C1 (Maunus) 59/60 (98\%), and TWP/C2 (Nauru) 59/60 (98\%). Reduced recovery at NSA was due to bad weather preventing either access to the Great White or launches because of blowing snow or high winds.

\subsubsection{Make Atmospheric Radiation Measurement Program-Barrow Soundings Available to the Global Telecommunication System}

STATUS - Soundings from SGP and NSA (Barrow) are now available to the GTS. Soundings from TWP (Manus and Nauru) will also be available to the GTS once the new DigiCORA-III systems are installed and operational there.

\subsection{Broadband Radiometers (SIRS, SKYRAD, GNDRAD, BRS)}

Mentor: Tom Stoffel, National Renewable Energy Laboratory

Broadband Radiation System (BRS) data for December 2006 were excellent with 100\% data collection and more than $95 \%$ of the shortwave and $100 \%$ of the longwave data passing automated data quality tests. SIRS data for December 2006 were generally excellent with 100\% data collection except at E5 (46\%), E10 (96\%), E15 (91\%), E18 (77\%), and E19 (95\%). SKYRAD data for December 2006 was excellent with $100 \%$ data collection at all stations (NIM, NSA, and TWP). Of the 1-minute irradiance data collected, $99 \%$ of the shortwave and $100 \%$ of the longwave data passed automated data quality tests except at Darwin (TWP/C3) from 12/13/06 (04:00 GMT) through 12/31/06 (23:59 GMT) - direct normal shortwave irradiance data are incorrect due to pyrheliometer failure. 
Continued small (approximately 20 to 50 Watts per square meter) discrepancies and intermittent data inconsistencies among coincident measurements of 1-minute averaged global, direct, and diffuse broadband irradiances continue. Clear-sky discrepancies are generally limited to early morning and late afternoon when the solar zenith angle is greater than 80 degrees. Measured global is generally less than the summed direct and diffuse. Similar discrepancies occur during partly cloudy conditions during any daylight period. The sources of these apparent discrepancies can be attributed to radiometer measurement characteristics. Angular response: variation of calibration coefficients, termed Responsivity (Rs), with solar zenith angle $[\operatorname{Rs}(Z)]$; time constant: varying time response characteristics of thermopile-based instruments; and, thermal offset errors: effects of infrared (sky) radiation on the pyranometer output signal. Each of these measurement issues remains under study.

\subsubsection{Pyrgeometer Calibration Improvements}

Tom Stoffel and Ibrahim Reda have initiated an investigation into the source of the bias in the ACRF pyrgeometer blackbody calibration system. Once the source of the bias is determined and corrected a careful validation of the system and a comparison of pyrgreometers calibrated with this and other systems will be conducted (ECO-00559).

At blackbody temperatures less than $-20^{\circ} \mathrm{C}$, the Dow Corning 200 fluid viscosity increases, which inhibits mixing and results in a temperature gradient of 1.5 to $2.0^{\circ} \mathrm{C}$ from the base to the top of the hemispherical blackbody. A new set of fluid dispersion manifolds (perforated annuli) has been developed to reduce the temperature gradients in the blackbody. Additionally, a replacement fluid with better low-temperature (viscosity) characteristics has been identified. Two five-gallon containers of this fluid will be acquired for evaluation at NREL. Pyrgeometers calibrated using the new manifold and fluid will be compared with pyrgeometers having calibrations traceable to the World Infrared Standard Group (WISG) and with pyrgeometers calibrated by NOAA/GMD.

STATUS - Acquisition of the replacement cooling fluid is on hold due to funding restrictions associated with the Continuing Resolution.

\subsubsection{Radiometer Calibration Facility Data Acquisition System Replacement (deferred to FY2008)}

The data acquisition system in the Radiometer Calibration Facility (RCF) used for annual Broadband Outdoor Radiometer Calibration (BORCAL) activities is over ten years old and needs to be updated. NREL has recently replaced their BORCAL data acquisition system using internal funds. The SGP system should be a duplicate of the NREL system for software compatibility and performance assurance.

\subsection{Carbon Dioxide Flux System}

Mentor: Marc Fischer, Lawrence Berkeley National Laboratory

The CO2FLX instruments at 4, 25, and $60 \mathrm{~m}$ on the SGP-CF tower are operating nominally with the exception of the net radiometers. During December, the CNR-lite net radiometer was returned to LBNL for re-calibration. It appears that the data from the downwelling long wave channel on the CNR-1 continues to be incorrect. 


\subsection{Carbon Monoxide System (CO)}

Mentor: Sébastien Biraud, Lawrence Berkeley National Laboratory

The CO system was operating nominally.

\section{$2.7 \mathrm{CO}_{2}$ (Precision Gas) System (PGS)}

Mentor: Margaret Torn and Sebastien Biraud, Lawrence Berkeley National Laboratory

The PGS is operating nominally.

\subsection{Cimel Sun Photometer}

Mentor: None (external data provided by National Aeronautic and Space Administration Aerosol Robotic Network)

NSA (Barrow) - Removed in mid-October for annual recalibration. It will be re-installed in March after the sun rises again in Barrow. AERONET will upgrade this instrument to add a channel at $1640 \mathrm{~nm}$ at no cost to ARM.

SGP (CF) - Reinstalled in early December. It is now collocated with the shortwave spectrometer optics on the Optical Trailer roof. Zenith radiance measurements are being added to the Cimel programming.

TWP (Nauru) - A new Cimel was installed in late November. The Cimel that had been at Nauru has been sent to AERONET for recalibration and upgrade to add a channel at $1640 \mathrm{~nm}$. It will then be sent to Germany where it will be swapped with the Cimel currently with the AMF.

AMF (Niamey) - Shut down in January at the conclusion of the AMF deployment.

\subsubsection{Internet Data Transfer}

The transfer of CSPHOT data from the Cimel instrument to AERONET using geostationary operational environmental satellite or Meteosat will be replaced with an Internet data transfer to improve reliability of the transfer, to permit ACRF personnel to monitor the transfer, and to allow the raw data to be acquired, ingested, and archived for use by ARM Science Team members (ECO-00555).

December 2006 - Internet transfer of CSPHOT data to AEORNET has been initiated at TWP-Nauru and SGP sites. 


\subsection{Disdrometer}

Mentor: Mary Jane Bartholomew, Brookhaven National Laboratory

Darwin was mostly rainy in December and experienced two storms with accumulations near $60 \mathrm{~mm}$. SGP had a few light rains early in the month that the tipping bucket did not observe (but the disdrometer did observe). The SGP also had storms on the $20^{\text {th }}$ and $30^{\text {th }}$ with $24 \mathrm{~mm}$ and $14 \mathrm{~mm}$ of precipitation respectively.

Deployment of an optical rain gauge at SGP would benefit measurement of light rain conditions that the tipping bucket gauges have difficulty with. This would also benefit ARSCL processing, which currently uses the moisture detector on the MWR at SGP-CF as a sensitive light rain detector.

\subsection{Energy Balance Bowen Ratio Station}

Mentor: David Cook, Argonne National Laboratory

Most EBBR stations are operating nominally. The severe winter storm that swept through southern Kansas and northern Oklahoma in late November - early December affected the operation of the automatic exchange mechanism (AEM) and therefore the data from several EBBR systems. The AEM at Earlsboro (E27) is scheduled for replacement in January. Observed biases between the EBBR net radiometer and SIRS radiometer suite are attributed largely to poor longwave sensitivity for low sky temperatures in the EBBR net radiometer. The schedule for recalibrating the EBBR sensors has been accelerated to ensure completion prior to the Cloud-LAnd Surface Interaction Campaign (CLASIC) in June.

Vaisala no longer supports the combined temperature and relative humidity probes in the EBBR (2 per system) but does still offer recalibration services. Replacement probes are available from the EBBR manufacturer. The mentor has proposed that replacement of all 32 probes be phased in over 3 years. As the old probes are replaced they can be used as spares for the systems not yet upgraded to the new probes.

\subsection{Eddy Correlation Station}

\section{Mentor: David Cook, Argonne National Laboratory}

SGP - All ECOR stations are operating nominally. The system at E10 (Tyro) was returned to service in January. The schedule for recalibrating the $\mathrm{CO}_{2}$ and $\mathrm{H}_{2} \mathrm{O}$ sensors has been accelerated to ensure completion prior to the Cloud-LAnd Surface Interaction Campaign (CLASIC) in June.

AMF - The $\mathrm{CO}_{2}$ concentration and flux data from the AMF ECOR are periodically affected by aircraft operations at the adjacent Niamey airport. 


\subsubsection{Add Wetness Sensors}

Periods of dew, frost, and precipitation often cause data from the $\mathrm{CO}_{2} / \mathrm{H}_{2} \mathrm{O}$ sensor and sonic anemometer to be incorrect. Adding a wetness indication would provide the data user with a more reliable source of information concerning this condition (ECO-00536).

STATUS - Testing of a wetness sensor on an Argonne ECOR system similar to those deployed by ARM began in mid-January.

\subsection{G-Band (183.3 GHz) Water Vapor Radiometer}

Mentor: Maria Cadeddu, Argonne National Laboratory

Occasional problems with the GVR software resulted in brief gaps in the data during December. GVR data are now available from the ARM Archive under the name nsagvrC1.b1. The measurements are in agreement with model computations. RFI is observed in all four channels.

\subsection{Global Positioning System (SuomiNet)}

Mentor: None (external data provided by SuomiNet/COSMIC)

SGP - Telecommunications problems at LeRoy (E3), Halstead (E5), and El Reno (E19) continue to affect data availability from these SuomiNet stations. All other SGP SuomiNet GPS stations and their associated meteorological sensors are operating nominally. Discrepancies between precipitable water vapor derived from MWRs (at SGP and Howard University) and SuomiNet have been attributed to errors in the processing for motion of the GPS stations due to continental drifts.

TWP - The temperature/relative humidity sensor associated with the Manus Island SuomiNet system was replaced on 16 October. The system is now operating nominally. In November the GPS receiver at Nauru failed. The unit will be repaired under warranty but must be returned to the U.S. for warranty service. Following this repair, the GPS receivers at Manus and Darwin will be returned to the manufacturer to have the defective component replaced prior to failure.

NSA (Barrow) - (System belongs to the University of Alaska at Fairbanks (UAF) and is installed at NOAA/CMDL site.) The temperature/relative humidity probe associated with the Barrow system failed in August 2005. In June, following discussions with UAF personnel, NSA personnel replaced the failed GPS met system with a spare from the SGP and returned the failed system to UAF for repair.

NSA (Atqasuk) - In June 2006 University Navstar Consortium (UNAVCO) personnel installed a GPS receiver at Atqasuk for geodetic purposes. The spare ARM GPS meteorological system currently in use at Barrow will be connected to this receiver once the UAF met system is repaired and returned to Barrow, then the Atqasuk station will be incorporated into SuomiNet to provide precipitable water vapor data. 


\subsection{In-situ Aerosol Profiling}

Mentor: John Ogren and Betsy Andrews, National Oceanic and Atmospheric Administration/Earth System Research Laboratory/Global Monitoring Division

There have been 675 IAP flights since the beginning of the program in March 2000 (through January 10, 2007).

The high (85\%) relative humidity nephelometer continued to have problems after being replaced in September. Diagnostic efforts are continuing. Also, the engine pump that draws sample air through the optical instruments failed in late December. Data from those instruments (nephs+psap) will be invalid from December 21 until the pump is repaired.

\subsection{InfraRed Thermometer}

Mentor: Vic Morris, Pacific Northwest National Laboratory

InfraRed Thermometers (IRTs) have been deployed at 12 SGP extended facilities (ECO-345), operating at $5 \mathrm{~Hz}$ sampling rate. IRTs are also part of the SKYRAD and GNDRAD systems at TWP, NSA, and AMF. These are currently sampled at $0.5 \mathrm{~Hz}$. Plans to increase the sampling rate of the SKYRAD IRTs to $5 \mathrm{~Hz}$ are in progress (ECO-00368).

The IRTs are operating nominally at all sites except SGP E13 and E19 where higher sky temperatures were measured than at other sites. For sky temperatures less than $-60^{\circ} \mathrm{C}$ the IRTs at SGP report higher sky temperatures than the AERI over the $10-\mu$ m pass band of the IRT. An IRT and its enclosure were sent to the manufacturer for diagnosis. They did not find any problems with the design of the enclosure/mirror system and suggested that the influence of the mirror on the measured temperature be accounted for.

\subsection{Multi-Filter Rotating Shadowband Radiometer and Related Systems (MFR, GNDMFR, NIMFR)}

Mentor: Gary Hodges, National Oceanic and Atmospheric Administration/Earth System Research Laboratory/Global Monitoring Division; John Schmelzer, Pacific Northwest National Laboratory

John Schmelzer has indicated he plans to retire in May.

SGP - 11 of 22 Extended Facilities do not have operational MFRSRs due to a shortage of spare sensor heads.

NSA - MFRSR, MFR, and NIMFR have been removed for the winter. John Schmelzer will refurbish and recalibrate them.

TWP - Operating nominally.

AMF - Operating nominally. 
Twice-per-day cleaning of the Normal Incidence Multi-Filter Radiometer (NIMFR) at SGP has been initiated to eliminate the step-change in the measurements observed following the current once-per-day cleaning events.

November 2006 - Gary Hodges traveled to several SGP extended facilities in October to investigate recurring shading problems with the MFRSRs. Gary found that most sites had 1-2 minor configuration problems and has recommended a change in the maintenance procedures for shading/alignment adjustment.

\subsubsection{Filter-Detectors}

ACRF has 50 multi-filter radiometers deployed in a variety of configurations including the MFRSR, the downward-facing MFR, and the NIMFR. The 6 narrow band $(10 \mathrm{~nm})$ filter-detectors in almost all of these sensors have degraded over time and are in urgent need of replacement. Perkin-Elmer has manufactured custom-designed and custom-built filter-detector assemblies to meet ACRF specifications (ECO-00580).

STATUS - John Schemelzer has built 90 new sensor arrays using the new filter-detectors and has used 40 of these to refurbish 40 MFRSR heads. So far, 6 of these have completed the calibration process and 3 have been sent to SGP for installation along with new Campbell data loggers.

\subsubsection{Multi-Filter Rotating Shadowband Radiometer Calibration and Data Processing Improvements}

Problems with the calibration and data processing of the MFRSRs were revealed during the ALIVE campaign (ECO-00571). Joe Michalsky convened a meeting at Pacific Northwest National Laboratory during the last week of January to discuss the calibration issues and develop a plan to address them. Participants included Gary Hodges, Patrick Disterhoft, Mikhail Alexandrov, John Schmelzer, Jim Barnard, Annette Koontz, Peter Armstrong, and Jim Liljegren. The details of the meeting and plan are given in ECO-00571. Nighttime measurements will be collected from the existing MFRSRs to derive an offset correction. New calibration processing will be implemented based on the consensus procedures developed during the meeting. Old data will be reprocessed to apply the offset corrections and the new calibration and processing procedures. Collection and ingest development are proceeding but have been delayed by the need to accommodate both the current proprietary data loggers and the new Campbell Scientific data loggers.

October 2006 - In October nighttime measurements were implemented on all MFRSRs at the SGP.

\subsubsection{Data Logger Replacement}

The proprietary data loggers supplied with the MFRSRs and related instruments are to be replaced with Campbell Scientific CR1000 data loggers. This will permit them to be more easily maintained. It will also permit modifications to the operation of the instruments and data acquisition to be easily implemented (ECO-00350). 
STATUS - John Schmelzer sent three new loggers and related equipment to SGP. Replacement of the MFRSR loggers will begin in January.

\subsection{Millimeter Cloud Radar}

Mentor: Kevin Widener, Pacific Northwest National Laboratory; Karen Johnson, Brookhaven National Laboratory

NSA/C1 - The TWTA power output dropped to a level where clouds are no longer being detected. The spare TWTA is at Applied Systems Engineering (ASE, the TWTA supplier) for a TWT replacement. The vendor has all the necessary components on hand to repair the TWTA but had no technical personnel on hand due to the holidays. Repair and shipment is expected during the first half of January 2007. As soon as the TWTA arrives in Barrow, Kevin will travel there to replace it and recalibrate the MMCR.

SGP/C1 - In December the MMCR started to experience intermittent filament under-voltage errors. Kevin Widener and Chris Martin are working with ASE to identify the source of the problem. The failed TWTA at Barrow will be returned to ASE for repair and may then be used to repair the SGP MMCR.

TWP/C1 (Manus) - 96.6\% up time in December. The power output of this system continues to decline. The TWT will need to be replaced in the next few months.

TWP/C2 (Nauru) - A new TWTA was installed by BoM technicians during their maintenance trip in lateNovember. This MMCR had 100\% up time in December.

TWP/C3 (Darwin) - The spare PIRAQ-III that was to have been installed at Barrow was instead installed at Darwin to replace the failed PIRAQ-III there. Replacement RF switches have also been installed. 93.5\% up time in December.

\subsubsection{MMCR Processor Upgrades}

(ECO-00283) Spectral imaging problems with the PIRAQ-III processor have been resolved at Darwin by installing newly developed filter coefficients. The spare PIRAQ-III processor will be installed in the MMCR at Darwin to replace the PIRAQ-III that failed. The NSA (Barrow) upgrade will be delayed until the failed processor is repaired or another spare is purchased.

\subsubsection{Add Polarization at Barrow}

(ECO-0052) September 2006 - The orthomode transducer has been received. Because the PIRAQ processor does not support polarization, the installation of the orthomode transducer at Barrow is on hold until the next processor upgrade.

\subsubsection{Spare Traveling Wave Tubes}

New traveling wave tubes (TWT) will be ordered to replace the TWTs originally delivered with the MMCRs, which are well beyond their rated lifetime and are beginning to fail (ECO-00425). 
STATUS - The first TWT delivered to SGP was incorporated into a TWTA and sent to Nauru to repair the MMCR there. Two more TWTs have been received, which will go to Manus and Barrow. Two additional TWTs have been ordered as spares.

\subsubsection{Millimeter Wave Cloud Radar Spectra Processing}

Spectra files produced by the upgraded MMCRs (C40 or PIRAQ-III processors) range from 8 to 15 Gigabytes per day. Algorithms for eliminating clear-sky periods and compressing the files need to be developed and implemented locally (ECO-00391).

STATUS - The compression algorithms have been implemented at SGP.

\subsubsection{Refurbish Millimeter Wave Cloud Radar Antennas}

Beginning in 2007, over a three-year period the MMCR antennas will be refurbished and characterized on an antenna range (ECO-00551).

STATUS - The antenna is complete and the contract for the new feed and sub-reflector has been placed. Once these are complete, they will be installed on the antenna reflector and calibrated. The Barrow MMCR antenna will most like be refurbished first to avoid impacting planned IOPs at SGP.

\subsubsection{Radome or Radome Dryer}

The detrimental effect on the data of standing water on the current fabric radome has prompted the pursuit of a more satisfactory solution. Unfortunately discussions with potential suppliers have not been fruitful. This taskis currently on hold (EC-00275).

\subsection{Micro-Pulse Lidar}

Mentor: Rich Coulter, Argonne National Laboratory

New, polarized MPLs are operating at SGP, Darwin, Nauru, and Barrow.

SGP - Good data to greater than $15 \mathrm{~km}$ is normal during nighttime and 10-15 km during daytime with no additional averaging beyond the 3 second averaging time presently in use by the instrument itself.

NSA - The NSA system produced good data until 22 December 2006. After that time, the data are highly suspect, due to a problem with the detector. A replacement detector was sent to Barrow and successfully installed by NSA technicians on 12 January 2007. (The vendor-supplied training has paid off!)

TWP - The new MPL at Nauru has been working well. The Darwin MPL has been producing excellent data in spite of decreasing energy output; however, in mid-December a series of artifacts beginning at approximately $10 \mathrm{~km}$ and repeating at roughly $1 \mathrm{~km}$ intervals became apparent. Further investigation of these artifacts reveals that they first appeared in late November near $20 \mathrm{~km}$. This may indicate detector problem similar to those with the Barrow system. 
A VAP has been developed to produce a file with separated polarization states, averaged to 30 seconds. This will appear similar to the present MPL data in terms of averaging time. It will have two data streams, one for circular polarization and a second for cross polarization.

Rich Coulter and Tim Martin have developed and tested a means to automatically restart the new MPLs. This has not yet been implemented.

\subsubsection{Retrofit Spectra-Physics Lasers}

The type-1 and type-2 units use Spectra-Physics lasers that are no longer supported (except for the AMF unit, which uses a LiteCycles laser that is no longer supported). ARM has one spare Spectra-Physics laser head. Four old Spectra-Physics laser supplies have been retrofitted by Sigma Space to use Coherent F-System laser diode modules and two remain to be retrofitted (ECO-00362).

STATUS - Sigma Space Corp has upgraded the laser diode supplies from the type-1 MPLs at SGP and NSA. This will allow these type- 1 systems to serve as backup systems.

\subsection{MicroWave Radiometer}

\section{Mentor: Maria Cadeddu, Argonne National Laboratory}

SGP - Six MWRs were compared during October-November 2006: serial numbers 04, 10 (both from SGP/CF), 11 (SGP/B1), 12 (SGP/B5), 18 (SGP/B6), and 21 (NSA/C2). Differences of as much as $0.7 \mathrm{~K}$ in brightness temperatures at $23.8 \mathrm{GHz}$ (corresponding to $\sim 0.5 \mathrm{~mm}$ PWV) were observed between radiometers. Shipment of several of these radiometers to Radiometrics for diagnosis and repair has been delayed due to funding limitations under the Continuing Resolution.

AMF (Niamey) - Few RFI spikes were observed in the MWR data in December.

NSA/C2 (Atqasuk) - In October this radiometer was sent to the SGP central facility for inclusion in the MWR Inter-comparison IOP.

SGP/B5 (Morris) - In October this radiometer was sent to the SGP central facility for inclusion in the MWR Inter-comparison IOP.

SGP/B6 (Purcell) - In October this radiometer was sent to the SGP central facility for inclusion in the MWR Inter-comparison IOP. In December this radiometer was sent to Manus to replace the failed MWR there.

TWP/C1 (Manus) - This radiometer (\#15) experienced a failure in October. A replacement circuit card failed to restore operation. A replacement radiometer from SGP (\#18 formerly at SGP/B6) was shipped in December.

TWP/C2 (Nauru) - A replacement was installed in late November. The MWR has been returned to Radiometrics for service. 


\subsubsection{Unify MicroWave Radiometer Connectors}

The Impulse connectors on the 3 MWRs at the TWP sites make it difficult to substitute a spare MWR in case of a failure, as occurred in Darwin prior to TWP-ICE due to a lightning strike. Accordingly, the Impulse connectors are being replaced with the standard connectors used on all other MWRs.

STATUS - The MWR on Nauru has been swapped and returned to Radiometrics for replacement of the connectors and for repair. The MWR on Manus has also been swapped and is being returned to Radiometrics for repair and connector replacement.

\subsection{MicroWave Radiometer Profiller}

\section{Mentor: Maria Cadeddu, Argonne National Laboratory}

NSA (Barrow) - Data for this month are generally good and continuous. The retrieved 2-channel LWP is consistent with the MWR retrievals, however the 6-channel retrieval shows a progressive drift towards negative values, reaching a negative LWP $\sim 0.05 \mathrm{~mm}$ by the end of the month. Because the drift is not observed in the two-channel retrieval it is likely that there is a drift in the 51-GHz channel, which requires recalibration with liquid nitrogen.

AMF (Niamey) - Calibration of the 51-GHz channel is still an issue. On 5 May a power outage affected the calibration. Liquid nitrogen is required to recalibrate the $51-59 \mathrm{GHz}$ channels, but is difficult to obtain in Niamey. The calibration shift affects the 6-channel retrieval of LWP that has a positive bias of about $0.05 \mathrm{~mm}$ with respect to the two-channel retrieval beginning on $5 \mathrm{May}$.

\subsection{Narrow Field of View Radiometer (NFOV)}

Mentor: None

The Narrow Field of View (NFOV) radiometer has been removed from service at SGP and sent to NASA GSFC for calibration using the AERONET facilities. It will be deployed with the AMF in Germany.

Christine Chiu reports that the calibration at NASA GSFC resulted in good agreement with a Cimel sunphotometer at $940 \mathrm{~nm}$, but poor agreement at $673 \mathrm{~nm}$. The NFOV will be returned to PNNL to replace the filter-detector at $673 \mathrm{~nm}$. This may delay its deployment to Germany.

\subsection{Raman Lidar}

Mentor: Diana Petty, Pacific Northwest National Laboratory

Analysis of the signal strength in the WFOV and NFOV Nitrogen channels suggests that the signal strengths have declined significantly since 2004. The decrease is evident in the peak signals as well as in the background signals which rules out degradation of the laser as a reason. One possible cause for the loss of sensitivity could be a degradation of the mirrors in the telescope (which was the cause of the loss of sensitivity in 2002-2003). A "witness sample" that was created when the telescope mirrors were resurfaced in 2004 was sent back to the recoating firm to have its reflectivity measured. Their 
measurement shows that the reflectivity of the witness sample is down approximately $10 \%$ relative to the measurement that was provided when the telescope mirrors were coated. If this and the original measurement (performed in 2004) are correct then this could explain the observed degradation. However, the vendor does not trust the original reflectivity measurement and thus the telescope cannot be positively identified as being the cause for the degradation. A second possible cause for the loss of sensitivity could be that the transmission of the interference filters has degraded. The filter manufacturer does not believe that this could have occurred, but is willing to measure the transmission of one or more of the interference filters for free to confirm or reject possible degradation in the transmission characteristics of the interference filters. The filter from the narrow field-of-view nitrogen channel will be replaced by a spare and sent to the vendor for those measurements.

Work on the MERGE algorithm that combines the analog detection and photon counting data continues, as a $10 \%$ bias in the water vapor mixing ratio persists. To assist with this work, a photomultiplier, base, and housing have been sent to Licel Electronics in Germany for testing with their equipment.

Temperature profile retrievals are adversely affected by high solar background noise during the daytime. This is believed to be due to out-of-band leakage into the rotational Raman channel. Adding a wider band filter to block the leakage is being considered.

\subsubsection{Add Automatic Alignment System}

Due to small thermal gradients in the laser and the lidar enclosure, the alignment of laser beam in the detectors' field-of-view (FOV) changes with time, which can affect the data quality, sometimes substantially. To address this operationally, the laser beam is swept through the detectors' FOV using a pico-motor controlled steering mirror to find the optimal location. This "alignment tweak" is scheduled to occur every 3 hours. Accounting for the potentially 3-hourly changes in alignments is the single largest uncertainty in the data processing codes. It affects all measurements, but the aerosol extinction measurements and the temperature profiles seem to be the most sensitive. Licel has recently developed a new product that permits the alignment of the lidar to be actively maintained (ECO-00586). The Licel alignment sensor was delivered in September.

STATUS - Licel has recently made improvements to the alignment sensor and has exchanged the original sensor for a new one. Installation has been rescheduled for April 2007.

\subsection{Rotating Shadowband Spectrometer}

\section{Mentor: Peter Kiedron, State University of New York at Albany}

The RSS is operating nominally. Field calibrations are nominal. Automatic processing of calibration data is under development by Peter Kiedron and Jim Schlemmer. 


\subsection{Radar Wind Profiler - $915 \mathrm{MHz}$}

Mentor: Rich Coulter, Argonne National Laboratory

SGP - Currently, all systems at SGP are operating nominally. The SGP/C1 (central facility) and SGP/I3 (Meeker) have had the digital receiver upgrades successfully installed. The problem with RASS data being "reflected" at large range gates has mysteriously improved recently.

NSA - System crashes frequently. Maybe the upgraded hardware, LAPXM software, and new computer will (eventually) help resolve this problem.

AMF (Niamey) - Operating nominally.

\subsubsection{Upgrade to Digital Receivers}

The four $915 \mathrm{MHz}$ RWPs at the SGP are now 9-13 years old and are exhibiting increasingly frequent, strange, and expensive-to-repair failures. This may pose problems for CLASIC, scheduled in 2007. Due to the age of these systems, parts are increasingly difficult to obtain (Vaisala no longer has exact replacements for some items; the available parts must be modified for use in our systems). Vaisala offers an upgrade for these systems that will replace the present interface, receiver and computer (including DSP board) with new components and will include the latest version of LAPXM, the operating system. The systems at SGP/CF and SGP/I3 will be upgraded. The systems at SGP/I2, SGP/I3, and NSA/C1 will be upgraded in 2007 (ECO00567).

\subsection{Radar Wind Profiler - $50 \mathrm{MHz}$}

Mentor: Rich Coulter, Argonne National Laboratory

In January the $50 \mathrm{MHz}$ RWP at the SGP ceased transmitting. The transmitter was returned to ATRAD in Australia for diagnosis and repair. After reinstalling the transmitter the output power was still zero. The power tube was replaced but the output power is still zero. Vaisala has loaned SGP test equipment to help diagnose the problem. The system is currently out of service.

STATUS - Discussions with Vaisala about this problem are on-going.

\subsection{Soil Water and Temperature System}

Mentor: John Harris, University of Oklahoma

Nothing to report.

\subsubsection{Replace In-Ground Sensor Arrays}

The in-ground sensors for the SWATS deployed at all 22 SGP Extended Facilities (EFs) are arranged in two redundant vertical arrays so that if/when a sensor fails, there is a redundant sensor at the same level. This is necessary because disturbing the soil to replace a failed sensor adversely affects the measurements 
for 6-12 months afterward depending on soil type. At this time 8 of the 22 SWATS installations have at least one failed sensor, and 5 sites have 2 or more failed sensors. These sensors cannot be replaced without disturbing the soil and invalidating the measurements at all levels. To address this problem, new redundant sensor arrays will be installed at the SGP EF sites. These will be installed in a phased manner: 5 sites per year over the next 4 years beginning in 2005 with the sites having multiple failed sensors given highest priority. After the soil recovers from the installation process in 6-12 months, the new sensor array will be connected to the existing SWATS data acquisition system in place of the old sensor array (ECO-00493).

September 2006 - Don Bond installed replacement sensor arrays at the first two sites in late March. In May, John Harris and Don Bond installed new sensor arrays at three Extended Facilities to replace old sensors that have ceased to function. These sensors were installed at Lamont (EF-13/CF-1) down to a depth of $60 \mathrm{~cm}$, at El Reno (EF-19) down to a depth of $175 \mathrm{~cm}$, and at Meeker (EF-20) down to a depth of $85 \mathrm{~cm}$. New sensors for the next five sites to be replaced in the fall have been ordered.

\subsection{Shortwave Spectrometer (SWS)}

Mentor: Scott Kittelman, University of Colorado

On January 11, 2006, the Shortwave Spectrometer was reinstalled and calibrated at the Southern Great Plains Central Facility by Warren Gore and Tony Trias from NASA Ames.

\subsection{Surface Meteorological Instrumentation (SMET, SMOS, SURTHREF, THWAPS, MET, ORG, PWS)}

Mentor: Mike Ritsche, Argonne National Laboratory

SGP (SMOS) - All systems are operating nominally. Large data gaps at Halstead (E5) due to communications problems. New Vaisala temperature/relative humidity probes received (15) to replace old probes no longer supported by Vaisala (EWO-11056).

TWP (SMET, ORG) - All systems are operating nominally. The barometer at Nauru failed in early December.

NSA (METTWR) - Icing continues to be a problem with the wind direction sensors, which do not have a heater in the vane. Ice accumulates on the vane and causes the direction measurements to become sluggish (standard deviations at or near 0 ). This problem is worse in the transition months when the snow is much wetter and is more likely to stick to the vane.

AMF (MET, ORG) - The ORG continues to be underreport relative to the PWS and non-ACRF tipping bucket rain gauge. Adding a tipping-bucket rain gauge for the deployment to Germany may be helpful. 


\subsubsection{Develop Dynamic Rain Gauge Calibration Facility}

The tipping bucket rain gauges at the 15 SGP/EF sites with SMOS are currently calibrated using only a "static" calibration: a measured volume of water is poured into the gauge and the number of bucket tips is checked to ensure they correspond. In reality, as the rain rate increases and the bucket tips more frequently some rain is not collected. The purpose of the dynamic calibration is to determine the correction factor as a function of rain rate to account for this behavior (ECO-00495).

STATUS - Problems have developed with the software developed by the University of Iowa that have prevented successful calibrations from being obtained. An alternative approach has been proposed (ECR606) but will be deferred until higher priority instrument procurements are completed.

\subsubsection{Create Atmospheric Radiation Measurement Program Climate Research Facility Wind Sensor Repair Facility}

Rather than return ACRF wind sensors to the manufacturer for repair, it is cost effective and far quicker to perform the repairs and calibrations on-site. Repair facilities will be established at the SGP central facility and the TWP Darwin site (ECO-00561).

December 2006 - All necessary components have been received at SGP; spare parts are in route to TWP. Testing and repair procedures have been prepared and distributed to the SGP and TWP Site Operations Teams. SMOS and THWAPS wind sensor checks will begin soon.

\subsubsection{Upgrade T/RH Probes and Wind Sensors for NSA Met Systems}

Ice develops on the wind vanes, cup anemoneters, and aspirator inlets for the temperature and relative humidity sensors, which clog and affect the data quality. To alleviate these problems the mentor has proposed to replace the wind speed and direction sensors at NSA (both Barrow and Atqasuk) with sonic anemometers, and to replace the temperature and relative humidity probes with new, heated probes designed to operate in cold environments (ECO-00595).

STATUS - Deferred until higher priority instrument procurements are completed.

\subsection{Tandem Differential Mobility Analyzer}

Mentor: Don Collins, Texas A\&M University

Don Collins presented a poster at the 9th Symposium on Atmospheric Chemistry at the American Meteorological Society meeting in San Antonio entitled "The Atmospheric Radiation Measurement Program tandem differential mobility analyzer: Instrument description and summary of the first year of data.”

Data from the Tandem Differential Mobility Analyzer (TDMA) are currently acquired and processed by Don Collins. Processed data are then delivered to ACRF on a monthly basis and stored in the IOP area of the Archive as "beta-data." An ingest is being developed to produce netcdf files for inclusion in the main Archive (ECO-587). 


\subsection{Total Sky Imager}

Mentor: Vic Morris, Pacific Northwest National Laboratory

SGP - Operating nominally. Birds occasionally perch on system, affecting the imagery. Deterrents have been installed.

TWP (Manus) - In early July rust spots suddenly developed on one-half of the mirror. Communication with the mirror control board failed in late August. The mirror was replaced in mid-October; several unsuccessful attempts were made to re-establish control of the shadowband. The instrument has been sent to Darwin for repair.

NSA - Operating nominally. On October 30 the TSI stopped collecting data because the sun will not rise more than $5^{\circ}$ above the horizon until February. The instrument has been removed and will be stored until the sun is again $5^{\circ}$ above the horizon.

AMF - Operating nominally.

New, improved mirror controllers are being developed by Ray Edwards at Brookhaven National Laboratory.

\subsection{Meteorological Tower Systems}

Mentor: David Cook, Argonne National Laboratory

60-m tower at SGP C1 (central facility) - nominal operation.

21-m tower at SGP E21 (Okmulgee) - nominal operation.

40-m tower at NSA C1 (Barrow) - problems due to ice formation on temperature/humidity sensors and on the wind direction vanes continue. Replacement of these sensors with sonic anemometers and heated temperature/humidity probes has been proposedis being considered (ECO-00595).

David has begun planning for annual tower maintenance at SGP and NSA.

\subsection{Vaisala Ceilmeter}

Mentor: Vic Morris, Pacific Northwest National Laboratory

Operating nominally at all sites. Electronic ringing in the backscatter plot is visible at SGP-B5

(Morris, OK), but this does not affect the instrument's ability to detect clouds.

The standard unit at Darwin was replaced with a ceilometer having a "tropical” window. The ceilometer used in the Nauru Island Effect Study was returned to Vaisala for repair. 


\subsection{W-band (95 GHz) Atmospheric Radiation Measurement Program Cloud Radar}

Mentor: Kevin Widener, Pacific Northwest National Laboratory

SGP - Operating nominally; 100\% up time in December.

AMF (Niamey) - A 15 GHz oscillator failed in December. The radar has been shipped to ProSensing for warranty repair then will be reinstalled at the AMF site in Germany. 


\section{Future Instrumentation Planning}

In this section instrumentation that have been proposed for future acquisition and discussed by the Science Team Working Groups - but not yet approved for purchase - are presented along with any status information.

Acquisition of all new instrumentation is on hold pending the prioritization of instrument needs by the ARM Science Team Executive Committee and the resolution of the Federal budget situation.

\subsection{Atmospheric Radiation Measurement Program Volume-Imaging Array}

The ARM Volume-Imaging Array (AVA) is a proposed radar system to be deployed at the ARM SGP site to address the ARM program's need of mapping 3D cloud and precipitation structures at short to medium ranges (i.e., 20-75 km). The AVA system will provide time-resolved 3D precipitation fields, domain-averaged rainfall rate, cloud coverage throughout a volume, cloud-top heights, hydrometeor phase information (using polarization), horizontal and vertical variability of clouds and precipitation, and low-level convergence and divergence using dual-Doppler techniques. Principal elements of the AVA proposal prepared by Pavlos Kolias include:

- Three networked scanning radars arranged in a triangle with 20-30 km legs: one operating at $35 \mathrm{GHz}$ (same 8.6-mm wavelength as the MMCR) and capable of scanning the vertical region probed by the current MMCR, and two radars operating at $9.4 \mathrm{GHz}$ (3.2-cm wavelength, so-called "X-band”). All three radars will be transportable, scanning, polarimetric and Doppler.

- Development of a useful 3D cloud Value Added Product (VAP) similar to the existing ARSCL but on a regular 3D grid.

- Development of an “AVA Simulator.” Patterned after the well-known ISCCP Simulator, the AVA Simulator will perform forward simulations of radar observables, using as input LES model and cloud-resolving model outputs of cloud properties together with the characteristics of the AVA radars. The results will be used to develop and optimize volumetric radar scanning strategies, develop and evaluate inverse retrieval techniques, and develop prototype 3D ARSCL-like VAPs for the ARM community.

- A collaborative effort with the Center for Interdisciplinary Remotely-Piloted Aircraft Studies (CIRPAS) to deploy the CIRPAS 9.4-GHz phased-array radar at the ARM SGP site every year for 1-2 months of continuous observations.

STATUS - Consideration of the AVA, as such, has been deferred until 2008 when simulations have been carried out to demonstrate its capabilities and further refine its requirements. 


\subsection{Portable Raman Lidar}

Leosphere http://www.lidar.fr/ offers a portable MPL-type lidar that can be augmented with Raman capability. Raymetrics http://www.raymetrics.gr/(sold by Kipp \& Zonen) also offers a Raman Lidar. Both concerns have been invited to deploy their systems at SGP for comparison with the SGP Raman Lidar and MPL. Leosphere is planning to deploy a lidar at the SGP in late October.

October 2006 - Iwona Stachlewska of Leosphere deployed their non-Raman EZ Lidar at the SGP on 19 October for comparison with the ARM MPL system. Leosphere expects to have a commercial Raman system available in mid-to-late 2007. Raymetrics will not be able to furnish a demonstration Raman lidar system.

STATUS - Clarification of the scientific requirements for a portable Raman lidar is necessary before proceeding.

\subsection{Absolute Scanning Radiometer}

To provide an absolute IR flux reference, which could be used to calibrate the Eppley PIRs, Ells Dutton has suggested that ARM develop an Absolute Scanning Radiometer (ASR). This instrument would be functionally equivalent to an ASR developed by Rolf Philipona for the WMO. This instrument would not be used for routine data acquisition, but instead would provide a calibration reference. As such it would participate in WMO inter-comparisons at Davos, Switzerland every five years. Although an Small Business Innovation Research (SBIR) solicitation for an ASR was issued circa 2000, no successful proposals were received. Ells Dutton, Tom Stoffel, and Joe Michalsky are planning to develop a specification so that ACRF may send out a request for proposals to identify interest and cost for such an instrument.

\subsection{High-Resolution Oxygen A-Band and Water-Band Spectrometer}

Qilong Min has submitted a proposal to build an A-band spectrometer for ARM following his presentation to the Cloud Properties working group in October 2004 on this topic. The 3-year proposal and budget were sent out for technical reviews. The technical reviews, along with the proposal and budget, were then provided to the STEC. The STEC directed Qilong to present his plan and budget to the Cloud Properties working group at their November 2005 meeting for prioritization. Qilong presented a revised work plan (water-band/cloud phase components removed) and has submitted a revised budget.

\subsection{Rotating Shadowband Spectrometer Overhaul}

Peter Kiedron has demonstrated that the RSS built by Yankee Environmental System is capable of providing valuable measurements of direct, diffuse, and global spectral irradiance. Peter has also identified problems with the RSS that affect the stability of its calibration and the linearity of its response. Peter has recommended that the RSS be removed from service and sent to him at SUNY-Albany for a complete overhaul. 


\subsection{Add 1.6 :m Channel to Multi-Filter Rotating Shadowband Radiometer and Narrow Field of View}

Alexander Marshak has recommended that ARM support the development of a NFOV radiometer at $1.6 \mu \mathrm{m}$ to permit the retrieval of droplet size distribution. Andy Lacis and colleagues have suggested a $1.6 \mu \mathrm{m}$ channel be substituted for the unfiltered (broadband) channel in the MFRSR. A cursory examination of Perkin-Elmer's web pages reveals Indium-Galium-Arsinide (InGaAs) detectors are available that operate in this spectral region. This would require a development effort.

July 2006 - Two InGaAs detectors and two $1.6 \mu \mathrm{m}$ filters have been purchased to determine the feasibility of implementing them in the MFRSR and/or NFOV. In the MFRSR this filter-detector would replace the unfiltered (broadband) channel. Because the unfiltered channel is now being used in a broadband radiometer best estimate VAP for quality checking purposes, only a limited number of MFRSRs would be modified to accept a $1.6 \mu \mathrm{m}$ channel.

\subsection{Aerosol Particle Sizing Spectrometer to Replace Optical Particle Counter at Southern Great Plains}

John Ogren has suggested replacing the aging Optical Particle Counter (OPC) included in the SGP AOS with a new Aerosol Particle Sizing Spectrometer (APS) to be integrated into the existing TDMA.

\subsection{Future Microwave Radiometers}

The 2-channel MWRs range between 6-13 years old. They are no longer being manufactured; Radiometrics has replaced them with an instrument that sequentially tunes to 5 frequencies in the 22-30 GHz range. Although Radiometrics continues to support the MWRs, it is useful to begin considering replacements for these instruments. Although $5 \mathrm{~K}$-band channels may provide more robust retrievals than 2 channels, RPG offers a comparably priced 3-channel radiometer $(23.8,31.4,90.0 \mathrm{GHz})$ that could also be considered because it increases the sensitivity to thin liquid water clouds. It is also desirable to acquire a final, "production" version of the $183 \mathrm{GHz}$ microwave radiometer developed by ProSensing under a U.S. Department of Energy (DOE) SBIR Phase II award and deployed at Barrow since April 2005.

\subsection{Modified Muti-Filter Rotating Shadowband Radiometer for Liquid Water Path}

Qilong Min has proposed to modify the existing MFRSRs to permit him to retrieve liquid water path. Software modifications would be required to position the shadow band at several additional angles near the solar disk; modifications to the shadow band would be needed to either narrow it or increase its distance from the diffuser. A narrower diffuser (and modification to the sensor head) and an improved stepper motor and motor controller have also been proposed. A first phase might utilize a Rotating Shadowband Radiometer loaned to Min from Brookhaven National Laboratory. 


\subsection{Infrared Thermometers for the Southern Great Plains Extended Facility Sites}

Six IRTs were purchased in FY 2004, 9 additional IRTs were purchased in FY 2005. Some of these have been deployed with the AMF. Twelve SGP EF sites are currently equipped with IRTs; 10 additional IRTs would be needed to permit an IRT to be deployed at all 22 SGP extended facilities. 


\section{Small Business Innovation Research}

The DOE SBIR web page is at http://www.er.doe.gov/sbir/

\subsection{Eye-Safe Ultraviolet Backscatter Lidar for Detection of Sub-visual Cirrus (FY 2006)}

Based on recommendations from the 2004 Cloud Properties working group meeting, this subtopic was substituted for the A-band spectrometer subtopic. Connor Flynn is the technical contact. Phase I funding was awarded to Aculight Corporation: "Eye-Safe ultraviolet Backscatter Lidar for Detection of SubVisual Cirrus” http://www.science.doe.gov/sbir/awards_abstracts/sbirsttr/cycle24/phase1/039.htm

and to Physical Sciences, Inc.: "Field-Worthy ultraviolet Backscatter Lidar for Cirrus Studies." http://www.science.doe.gov/sbir/awards_abstracts/sbirsttr/cycle24/phase1/044.htm

\subsection{Instrumentation for Remotely Sensing Aerosol Optical Properties - Aerosol Phase Function (FY 2006)}

Based on recommendations from the Aerosol working group, this subtopic was added to the aerosol measurements subtopic. Phase I funding was awarded to Aerodyne Research, Inc.: "CAPS-Based Particle Single Scattering Albedo Monitor.”

http://www.science.doe.gov/sbir/awards_abstracts/sbirsttr/cycle24/phase1/040.htm

\subsection{Unmanned Aerospace Vehicle-Suitable Cloud Radar (FY 2006)}

Phase I funding was awarded to ProSensing, Inc: "High-Power, Pod-Mounted W-band Cloud Radar for Unmanned Aerospace Vehicles (UAV).”

http://www.science.doe.gov/sbir/awards abstracts/sbirsttr/cycle24/phase1/045.htm

\subsection{Radiometer Radiosonde (FY 2006 National Science Foundation Solicitation)}

The objective is to obtain a radiosonde with an onboard radiometer suitable for accounting for the radiative heating of the temperature sensor in the upper atmosphere. This is potentially interesting to ARM as a means for directly measuring the heating rate profile. Global Aerospace was awarded Phase I funding:

http://www.nsf.gov/awardsearch/showAward.do?AwardNumber=0539943

July 2006 - Matt Heun of Global Aerospace inquired about ARM's requirements for heating rate profile measurements. The BBHRP focus group provided their requirements to Matt. Matt and his colleagues have determined that, within the context of their current NSF SBIR project, they cannot control the tilt of the radiometers sufficiently to achieve the accuracy requirements provided by ARM; however, this could become the subject of a future DOE SBIR subtopic. Global Aerospace representatives have been invited at attend the ARM Radiative Heating Profile Workshop being organized by Warren Wiscombe. 


\subsection{In-situ Measurement of Cloud Properties with Large Sample Volumes (FY 2007)}

Warren Wiscombe contributed the following sub-topic and will be the technical contact.

The DOE ARM Program was formed to study the climatic effects of clouds. These effects, particularly how clouds respond to climate change (the so-called "cloud feedback" problem), are large yet poorly understood from both a measurement and modeling point of view (cf. Stephens 2005). Currently, there is a huge gap in spatial scale between in-situ measurements of cloud properties, typically from aircraft and balloons whose instruments have sample volumes on the order of cubic centimeters, and remote sensing retrievals of cloud properties, which have sample volumes ranging from tens of cubic meters (radar and lidar) to thousands of cubic meters (satellites). Most acute is the fact that in-situ measurements at a particular point give no information on the vertical distribution above and below that point, while active remote sensing retrievals typically give instantaneous vertically-resolved information. Since clouds are inhomogeneous down to centimeter scales, there is a complete lack of comparability between in-situ measurements and remote retrievals; simple assumptions of homogeneity to scale up the in-situ measurements are certainly false. Clouds also evolve considerably in the course of a minute, and thus methods, which are slow in time (such as a balloon ascending, or an aircraft ascending or descending) fail to capture the instantaneous state which remote sensing sees. Thus, there is a great need for in-situ measurements which have fast vertical reach and much larger sample volumes, ranging from cubic meters to hundreds of cubic meters, in order to allow meaningful comparisons with surface and satellite retrievals of cloud properties. Without confidence in those surface and satellite retrievals, which are our only way to extend our reach to the whole planet, it is impossible to make progression key global change issues concerning cloud feedbacks on global warming.

Therefore, grant applications are sought to develop instruments to measure cloud properties in-situ, for scales ranging from cubic meters to hundreds of cubic meters, with particular emphasis on fast vertical profiling above and below the in-situ platform. (The platform need not be a traditional aircraft or balloon; instruments for small UAVs, kites, gliders, and tethered balloons will also be considered.) An example of such an instrument can be seen in Evans et al. (2003). Measurements of the following cloud properties are particularly wanted, in order of decreasing priority for cloud-climate applications: (a) extinction coefficient at one or more wavelengths in the solar spectrum away from strong water vapor absorption bands; (b) total water content (liquid plus ice); (c) liquid and ice water content separately; (d) effective radius, defined as the ratio of the $3^{\text {rd }}$ to the $2^{\text {nd }}$ moment of the drop size distribution; (e) absorption coefficient or single-scattering albedo at one or more wavelengths in the solar spectrum away from strong water vapor absorption bands; (f) the scattering phase function for ice clouds; (g) the drizzle and precipitation fraction of the total condensed water content; (h) the supersaturation; (i) the dispersion, a measure of the width of the drop size distribution.

Stephens, G. 2005. "Cloud feedbacks in the climate system: A critical review.” Journal of Climate 18:237-273.

Evans, KF. 2003. "In situ cloud sensing with multiple scattering lidar: Simulations anddemonstration." Journal of Atmospheric and Oceanic Technology 20:1505-1522. 